\title{
Original Research \\ Challenges facing young African scientists in their research careers: $\AA$ qualitative exploratory study
}

\section{Save Kumwenda ${ }^{1,2}$, El Hadji A. Niang ${ }^{3}$, Pauline W. Orondo ${ }^{4}$, Pote William ${ }^{5}$, Lateefah Oyinlola ${ }^{6}$, Gedeon N. Bongo ${ }^{7,8}$, Bernadette Chiwona?}

1. College of Medicine, University of Malawi, Blantyre, Malawi

2. The Polytechnic, University of Malawi, Blantyre, Malawi

3. Laboratoire d'Écologie Vectorielle et Parasitaire (LEVP), Université Cheikh Anta Diop de Dakar, Sénégal

4. Kenya Medical Research Institute (KEMRI), Nairobi, Kenya

5. Department of Preclinical Veterinary Studies, University of Zimbabwe, Harare, Zimbabwe

6. Department of Food Science and Technology, Federal University of Agriculture, Abeokuta, Nigeria

7. Department of Biology, University of Kinshasa, Kinshasa, Democratic Republic of the Congo

8. Department of Veterinary Microbiology and Parasitology, Sokoine University of Agriculture, Morogoro, Tanzania

9. Chancellor College, University of Malawi, Zomba, Malawi

Correspondence: Mr Save Kumwenda (skumwenda@poly.ac.mw)

\section{Background}

Africa accounts for $14 \%$ of world's population, and the economies of most African countries are considered to be growing, but this is not reflected in the amount of research published by Africans. This study aimed at identifying the challenges that young African scientists face in their career development. Methods

This was a qualitative exploratory study involving young researchers who attended the Teaching and Research in Natural Sciences for Development (TReND) in Africa scientific writing and communication workshop, which was held in Malawi in September 2015. A semi-structured questionnaire was sent to all workshop participants who consented to taking part in the survey. In total, 28 questionnaires were sent via email and 15 were returned, representing a response rate of $53.6 \%$. Data were analysed using thematic analysis.

Results

Young Africans develop their research interests various ways. The most common career-promoting factors identified by the study participants included formal classroom learning, aspirations to attain academic qualifications, work satisfaction, and the desire to fulfill parents' dreams. Challenges cited by survey respondents included a lack of mentorship, funds, and research and writing skills. Lack of interest in research by policymakers, lack of motivation by peers, and heavy workload (leaving little time for research) were also reported as challenges. Respondents suggested that grants specifically targeting young scientists would be beneficial. Participants also urged for the establishment of mentorship programmes, increasing motivation for research, and more frequent training opportunities.

\section{Conclusions}

There is need for improved funding for institutional and research network strengthening in Africa, with particular attention given to expanding opportunities for young researchers.

\section{Introduction}

Research is important in the development and productivity growth of any nation. ${ }^{1,2}$ Unfortunately, in Africa there continues to be little investment in research. For example, in 2011, when worldwide expenditure on research was $1.77 \%$ of the total global gross domestic product, Kenya spent $0.1 \%$ of its $\mathrm{GDP}^{3}$ and South Africa spent $0.76 \%$ of its $\mathrm{GDP}^{4}$ on research. Declining investment in research has been cited as a reason for deteriorating research quality on the continent. ${ }^{5}$ In medicine, only $10 \%$ of research is performed in developing countries and only $2 \%$ of the 3000 journals from the developing world are listed in Medline. ${ }^{5}$ Recently, it was found that most Ebola research has been conducted in America. ${ }^{6}$ The Sustainable Development Goals promote research in all fields and for full research capacity in all countries by $2030 .^{7}$ This would improve performance in controlling emerging and re-emerging diseases that are greatly hampering progress towards targets in developing countries and support the information needs of decision makers at all levels.

The future of research in Africa rests in the hands of its young scientists, but there is little done to support them. ${ }^{9}$ The research profile of Africans is relatively new, and the process of building confidence and competence among young African researchers, in order for them to compete internationally, is at an early stage. Relevant research that informs policymaking is of insufficient quantity and quality in Africa, and the continent's political processes are not able to adequately evaluate and correct or compensate for existing shortfalls. Governments need researchers who invest their time in conducting thorough research using data on important and timely issues so that political decisions are informed by quality empirical evidence. This study aimed at finding out the challenges that young scientists face in their efforts towards contributing to development of the continent through their scientific work.

\section{Methods}

This was a qualitative exploratory study that involved young researchers who attended the Teaching and Research in Natural Sciences for Development (TReND) in Africa scientific writing and communication workshop in September 2015, held at Chancellor College, in Zomba, Malawi. A list of attendees and contact details was sourced from the workshop organisers. A semi-structured questionnaire was emailed to all workshop participants who accepted an initial invitation to take part in the study. There were 15 respondents from 28 questionnaires sent, representing a response rate of $53.6 \%$. Respondents were from Nigeria, Senegal, Ghana, Malawi, Zambia, Tanzania, Benin, Zimbabwe, Kenya, and the Democratic Republic of the Congo. All 15 participants were also involved in drafting or reviewing the manuscript. Questionnaire items mainly focused on personal attributes, how research interests developed, challenges faced, and any suggestions to improve research among young researchers in Africa. Completed questionnaires were received via email and analysed using thematic analysis with the help of NVivo 10 software. 
Table 1: Respondent characteristics

\begin{tabular}{|c|c|c|}
\hline Characteristic & Category & $\begin{array}{l}\text { Frequency }(\%) \\
(\mathrm{N}=15)\end{array}$ \\
\hline \multirow[t]{3}{*}{ Age } & $25-29$ & $4(26.7)$ \\
\hline & $30-39$ & $10(66.6)$ \\
\hline & $40+$ & $1(6.7)$ \\
\hline \multirow[t]{2}{*}{ Sex } & Male & $7(46.7)$ \\
\hline & Female & $8(53.3)$ \\
\hline \multirow[t]{9}{*}{ Country } & Benin & $2(13.3)$ \\
\hline & $\begin{array}{l}\text { Democratic Republic } \\
\text { of the Congo }\end{array}$ & $1(6.7)$ \\
\hline & Kenya & $3(20.0)$ \\
\hline & Ghana & $1(6.7)$ \\
\hline & Malawi & $2(13.3)$ \\
\hline & Nigeria & $3(20.0)$ \\
\hline & Zimbabwe & $1(6.7)$ \\
\hline & Tanzania & $1(6.7)$ \\
\hline & Senegal & $1(6.7)$ \\
\hline \multirow{4}{*}{$\begin{array}{l}\text { Number of } \\
\text { publications }\end{array}$} & 0 & $10(66.7)$ \\
\hline & 1 & $2(13.3)$ \\
\hline & 2 & $1(6.7)$ \\
\hline & 3 & $2(13.3)$ \\
\hline \multirow{4}{*}{$\begin{array}{l}\text { Highest } \\
\text { education }\end{array}$} & Bachelor's degree & $3(20.0)$ \\
\hline & Master's degree & $3(20.0)$ \\
\hline & Master's students & $6(40.0)$ \\
\hline & PhD students & $3(20.0)$ \\
\hline
\end{tabular}

\section{Results}

The study participants included 8 female and 7 male scientists, aged between 25 and 41 years. Five of the respondents had at least 1 publication in a peer-reviewed journal. All participants were either postgraduate students or holders of a bachelor's degree and working in a research institute (Table 1).

\section{Development of research interests}

Research interests in young people develop through various ways. Since research is a principal tool for graduate education, learning in a classroom at college followed by interactions with researchers were reported as the main initiators of research interests among the participants. A respondent from Kenya said as she was learning, she started thinking about who wrote the books she was reading. This made her think of how people generate new knowledge and inspired her interest in research. Others from Nigeria, Kenya, and Malawi also indicated that they always admired the intelligence of scientists. Classroom discussions about the scientific methods through which knowledge is generated stimulated their interest as learners. As learners, they always wanted to also be able to generate new knowledge and earn recognition or fame, like the scientists who discovered the theories being used in class. For example, in this study, a young woman from Nigeria, aged between 20 and 29 years, developed interest in research when she was in high school, through stories of great scientists, like Isaac Newton, told http://dx.doi.org/10.4314/mmj.v29i1.1 by her father. Some developed research interests through interactions with relatives who earn their living through research, while others developed their interests through the nature of their jobs, especially those working in universities. Teaching jobs in universities demand that one conducts research and publish in order to be promoted. This forces people to engage in research, and they subsequently continue this engagement. Some of the participants' responses on how interests in research were developed were as follows:

"My interest in research started during a research module during my undergraduate degree and currently through mentorship from a senior professional." (Female respondent, Kenya)

"My career as a research associate and a lecturer at a university ignited my interest in research. I believe that if I want to develop my career as an academic, I need to engage in research." (Male respondent, Senegal)

"I wanted to have a PhD so that I can be employable, and this created an interest in research. Then when I developed my proposal I started enjoying research on development of new and better drugs for mental illness." (Male respondent, Zimbabwe)

"I developed an interest in research because of my career as an academician. The interest developed because I wanted to contribute towards development of my country through writing, and this interest increased after being involved in coaching undergraduate students in research and also after noting that the requirement for promotion puts more emphasis in research at my institution." (Male respondent, Malawi)

"My interest in research developed since I was in high school. My father [told] me stories of great researchers like Isaac Newton from time to time, at a point the inquisitiveness to learn more about these scientists and tell my friends about them were exciting. This act generated much interest inside of me to the extent of following their path in order to become a great researcher in the future." (Female Respondent, Nigeria)

It has been shown that parents also play a big role in shaping the careers of their children. The above quote from Nigeria is evident that children value and desire to accomplish what parents see as important.

\section{Challenges faced during early research career}

Participants outlined different challenges they faced during their early careers. The first challenge was related to the sustainability of research ambitions. Respondents indicated that after developing the interest to start a career in research, they needed a lot of support to move forward, even just words of encouragement from peers. The most common support needed was mentorship from senior researchers. They indicated that most potential mentors are too busy with their work and have little time for junior researchers. A female researcher from Malawi said:

"When I first wanted to publish, I needed someone to assist me in turning my dissertation report into a publication. I approached two professors, but they kept postponing the meeting dates until I gave up."

Others said they needed support in terms of laboratory equipment and funding to allow for fieldwork and sample collection. Failure to acquire grants was a barrier, as most of the grants were too competitive for young researchers, especially given a lack of motivation from supervisors. Some quotations below indicate these and related sentiments:

"There is need for mentorship programmes and placement opportunities where young African researchers can be given opportunity to showcase their skills." (Female respondent, Zambia) 
"In order to realise our potential, there is need for grants that target upcoming scientists. There should also be trainings in proposal writing for research grants. Also, there is need for senior researchers to start engaging young scientists at every stage and not only when they want to generate data." (Male respondent, Senegal)

"In order for my interest to be supported I need some research grants. These can be offered by my university and not from outside the country because it will support my original ideas."

(Male respondent, Malawi)

Others indicated that no one else appeared to be interested whenever they talked about doing research and generating publications. They indicated that most young people focus on income during the first years of their careers, and that research is initially not financially rewarding. A common response was that governments and policymakers are not interested in research unless the results can directly influence policy, and this discourages most young people to consider research as a career option. Other respondents highlighted challenges related to publication as a major challenge. They indicated that one can conduct high-quality research but lack the skills to convert the work into a publishable manuscript. Other select responses describing early-career challenges for young researchers included the following:

"The main challenges here are lack of funds to young researchers. In terms of publishing, the main challenge is to know what to include in the paper from the research work." (Female respondent, Kenya)

"The main challenge I face as a young researcher is that most research grants require a lot of experience, and I am not considered even if I apply. They favour senior researchers. In academia, young people are not given the chance to lead." (Male respondent, Senegal)

"T also have problems in writing in English than in French. This puts me at a disadvantage when I want to publish in English journals. Also, the fees for language experts to proofread your manuscripts are very high." (Male respondent, Senegal)

"Our biggest challenge is lack of state-of-the-art laboratories where we can conduct high quality research. Also, there is lack of funding to support new innovative ideas; funders have their own ideas so we just follow them. The other challenge is that there is too much workload as an academician and this leaves us with little time for research." (Male respondent, Zimbabwe)

"Most senior researchers in Africa are too busy and do not have time to mentor the young ones. Most of them do not contribute enough if selected to be co-authors. This does not help the young scientists who aspire to publish in high impact journals." (Male respondent, Zimbabwe)

"I feel most young people don't know if they are required to do research. They believe that after graduation with a first degree, the next thing is to find a job and very few think about a career in research. Research is left to older people and those from developed countries who have secured funding for projects. Young ones do research just as an academic requirement." (Female respondent, Malawi)

"The most important challenge is that most people in my country are not interested in research. Most of the time, work demand does not give room for research. They just admire it but do not have time for it. This makes them less supportive to new ideas." (Male respondent, Benin)

"In my country less funding, poor infrastructure such as laboratories and computers, and lack of expertise in preparing http://dx.doi.org/10.4314/mmj.v29i1.1 manuscripts for publication are major setbacks for researchers. As a young researcher in my country, it is an uphill task to make transition from being a graduate student to being a faculty member. The availability of power supply to operate the equipment gives the research a snail speed most of the time, and finding an alternative source of power increases the cost of research. Above all, communicating research findings outside the academic community is not appreciated because the relationship between the government, the private establishment, and the research institution, as well as universities, is very weak. This makes applied researchers change to basic researchers and sometimes decrease the morale of the researcher." (Female respondent, Nigeria)

\section{Suggested strategies to mitigate the challenges faced}

Different suggestions were made by respondents on how to improve research among young scientists. Most of the suggestions related to the challenges that have been identified above. Below are some of the common responses:

"To maximise the potential that young African scientist have, there is need for constant mentorship and training. Once one paper is published, I hope I will have confidence to do more research and publish more." (Female respondent, Kenya)

"Experienced researchers should mentor young scientists to be like them rather than just using them to generate their data. In addition, issues of scientific writing [and] publishing should be integrated in the formal undergraduate and postgraduate programmes." (Male respondent, Senegal)

"Young researchers need to be supported with suitable equipment and mentorship to develop their ideas." (Male respondent, Zimbabwe)

"There is need to have open grants targeting the young researchers and more opportunities for PhDs at younger ages. Also, there is need for capacity building courses, and these could be integrated in the grant funding." (Male respondent, Zimbabwe)

"We need to find better means of making policymakers understand the link between research and development. They should also learn on how to support scientists, especially the young ones." (Female respondent, Malawi)

\section{Discussion}

It has been found that most respondents developed their research ambitions through the following means: classroom learning, ambitions to further academic qualifications, interaction with parents and other people involved in research, and through their jobs. The explanations of theories in classroom lessons and learning about those who developed some of these theories inspire students to start thinking of developing their own theories, and this is one foundation for research ambition. While some scientists develop their research interests early in life, others develop research interests during the process of acquiring postgraduate qualifications, such as master's or doctoral degrees. Furthermore, interactions with work colleagues and work experience are other sources of research ambitions. This means there are potential researchers all over the African continent, but they need to be nurtured so that they can contribute and compete internationally. Research capacity building courses, such as TReND in Africa's Science Writing and Communication School, are urgently needed. Such courses initiate long-term collaboration among the participants as well as the facilitators. Networking at these workshops and seminars can facilitate equitable research collaborations and personal relationships between individuals that can lead to formal partnerships sooner or later. The provision of courses in research design, statistical 
interpretation, and scientific writing can develop skills that are often inadequately developed in researchers. Furthermore, research capacity in certain African countries, such as South Africa, is more developed than other African countries; local capacity can be strengthened through regional partnerships.

From the responses gathered in this study, it is clear that there is need for African governments to start prioritising research funding and considering the needs of young researchers. Only if we invest in young researchers will Africa be able to come up with new innovations that are critical for its development. Hence investing in both young and senior researchers is very important if we are to achieve the Sustainable Development Goals by 2030. As identified by one respondent that most $\mathrm{PhDs}$ are late-career achievements in Africa, it is time that governments increase funding towards postgraduate studies. This will enable people to start their research careers earlier in life. This will lead to increased basic research output, which has been linked to economic growth. ${ }^{10}$

Africa accounts for $14 \%$ of the world's population and has some of the fastest growing economies in the world. ${ }^{11}$ With a growth rate expected to average $7 \%$ annually over the next 20 years, Africa is poised to become a leading source of innovation in a variety of industries. ${ }^{11}$ On this note, African researchers should be implored to remain focused, because they have immense potential to help address the challenges experienced in Africa. Researchers should also endeavour to work outside of their comfort zones in the pursuit of knowledge, make efforts for long-term collaboration with the developed world, and apply new knowledge to our continent through applied research. Continued dialogue between stakeholders, such as local research institutions and governments, will translate local research into action. Regular communication with regional and international policymakers is needed to understand global issues and priorities.

\section{Study limitations}

The small sample size and low response rate mean that the results are not representative of all young researchers in Africa, but the points raised form a good basis upon which to discuss and begin to address the challenges facing young scientists in Africa. Despite the small sample size, the results are applicable to most researchers in similar situations.

\section{Conclusions}

The challenges faced by young African researchers seem to be similar across all the participants who took part in this study. These challenges include scarcity of mentors, lack of funding, lack of writing skills, lack of motivation, and low demand for research by policymakers. Research capacity building courses, collaboration, and networking opportunities are urgently needed. The ideas compiled in this study contribute to the discourse on finding solutions to promote research in Africa, which will hopefully assist in the attainment of the Sustainable Development Goals by 2030 .

\section{Acknowledgements}

The authors would like to thank Dr Andrew Beale of TReND in Africa and Dr Sheila Ochugboju from the Training Centre in Communication (TCC) for their efforts in training the authors in scientific writing and communication. The authors would also like to thank Tolulope D. BisiAdeniyi, Chinenyenwa Ohia, James Majamanda, Yasinta Ganiza, Blessings Msikuwanga, Matrida Themuka, Aubren Chirwa, and Edwin Kagereki for their contributions to the study design and for providing some useful data during questionnaire administration.

\section{Competing interests}

The authors declare that they have no conflicts of interest.

\section{References}

1. Griliches Z. Issues in Assessing the Contribution of Research and Development to Productivity Growth. Bell J Econ [Internet]. 1979 Apr 1 [cited 2015 Nov 3];10(1):92-116. Available from: http://www.jstor.org/ stable/3003321

2. Kothari CR. Research Methodology: Methods and Techniques [Internet]. New Age International; 2004 [cited 2016 Sep 5]. 30 p. Available from: https://books.google.mw/books

3. Smith R, Monaghan M, Broad B. Involving Young People as CoResearchers Facing up to the Methodological Issues. Qual Soc Work [Internet]. 2002 Jun 1 [cited 2015 Sep 29];1(2):191-207. Available from: http://qsw.sagepub.com/content/1/2/191

4. Tamar K. SA's spending on research and development "to improve" [Internet]. Business Day Live. 2014 [cited 2016 May 12]. Available from: http://www.bdlive.co.za/national/science/2014/04/09/sas-spendingon-research-and-development-to-improve

5. Olukoju A. the crisis of research and academic publishing in nigerian Universities: the twentieth century and beyond. In: 28th Annual Spring Sysmposium. Dakar, Senegal; 2002.

6. Cruz-Calderón S, Nasner-Posso KM, Alfaro-Toloza P, Paniz-Mondolfi AE, Rodríguez-Morales AJ. A bibliometric analysis of global Ebola research. Travel Med Infect Dis [Internet]. 2015 Mar [cited 2015 Oct 10];13(2):202-4. Available from: http://linkinghub.elsevier.com/retrieve/ pii/S1477893915000344

7. United Nations. Transforming our world: The 2030 sustainable development goals [Internet]. UN; 2015 [cited 2015 Nov 4]. Available from: sustainabledevelopment.un.org

8. Alliance for Health Policy and Systems Research. Strengthening health systems: the role and promise of policy and systems research. [Internet]. Geneva: Alliance for Health Policy and Systems Research; 2004 [cited 2016 Aug 5]. Available from: http://www.who.int/alliance-hpsr/resources/ Strengthening_complet.pdf

9. Friesenhahn I, Beaudry C. "The global state of young scientist": project report and recommendations. ed. 1/2014. Berlin: Akad.-Verl; 2014. 63 p.

10. Jaffe K, Caicedo M, Manzanares M, Gil M, Rios A, Florez A, et al. Productivity in Physical and Chemical Science Predicts the Future Economic Growth of Developing Countries Better than Other Popular Indices. PLOS ONE [nternet]. 2013 Jun 12 [cited 2016 May 8];8(6):e66239. Available from: http://journals.plos.org/plosone/article?id=10.1371/ journal.pone.0066239

11. IBM Scientists. Developing solutions in Africa, for Africa and the world [Internet]. 2015 [cited 2016 Jan 24]. Available from: http://www. research.ibm.com/articles/africa.shtml. 